\title{
Construções de maternidade: experiências de mães de crianças com síndrome do intestino curto
}

\section{| ${ }^{1}$ Anita Paez, ${ }^{2}$ Martha Cristina Nunes Moreira |}

Resumo: Abordou-se a experiência de mães de crianças com uma grave condição crônica de saúde, a síndrome do intestino curto (SIC), a partir de um estudo que se deu em um hospital de referência no Rio de Janeiro no ano de 2014, contando com dez participantes. O objetivo do artigo é explorar aspectos da interpretação materna sobre a corporalidade dos bebês e seus efeitos na construção da maternidade. Foram utilizados o método biográfico e um roteiro de entrevista que propiciou a produção de narrativas. A interpretação dos dados, dialogada entre a hermenêutica de profundidade de Thompson e o interacionismo simbólico, reconheceu e valorizou o fato de que as construções da maternidade se inscrevem na ordem da interação. O corpo diferente, que parece desafiar a própria condição humana na interpretação materna, vai sendo significado e adquire intencionalidade. A dimensão de intersubjetividade inaugurada garante o reconhecimento do bebê. Conclui-se que os aparatos tecnológicos e cuidados especiais acionados para a sobrevivência de bebês com malformaçôes graves podem gerar um distanciamento e um sentimento de exclusão por parte das mães. A abordagem dessas mulheres precisa transcender o utilitarismo das práticas baseadas num "treinamento" dos cuidados.

> Palavras-chave: maternidade; síndrome do intestino curto; corpo; doença crônica; crianças.

\footnotetext{
1 Instituto Fernandes Figueira, Instituto Oswaldo Cruz. Rio de Janeiro-RJ, Brasil (anita.paez@ iff.fiocruz.br).

${ }^{2}$ Instituto Fernandes Figueira, Instituto Oswaldo Cruz. Rio de Janeiro-RJ, Brasil (moreira@iff. fiocruz.br).
}

Recebido em: 19/08/2015 Aprovado em: 07/06/2016 
Jamais o corpo humano conheceu transformações de grandeza e profundidade semelhantes às encontradas no decurso do século XX. Nas palavras de Schramm (1998, p. 218), "a práxis do homem contemporâneo mudou de escala, atingindo patamares nunca vistos antes: ela já não se limita à 'reforma' do mundo externo, mas alcança as próprias estruturas da matéria e da vida, inclusive a estrutura da vida humana”. A competência biotecnocientífica vem transformando nossas concepções mais arraigadas acerca da vida e da morte, saúde e doença, bem-estar e precariedade, assim como dos limites que podemos ou não ultrapassar, e por isso deve gerar questionamentos. (SCHRAMM, 1998).

Neste cenário, torna-se pertinente repensar o estatuto do corpo a partir do nascimento de crianças com malformações graves que, até há poucos anos, seriam incompatíveis com a vida. A interface entre a antropologia e a psicologia destaca uma questão que permanece fundamental para as ciências humanas: como devemos conceber os seres humanos? A resposta que dermos a esta questão é importante, porque ela estrutura não somente o que conhecemos atualmente sobre nós mesmos e os outros, mas também o que somos capazes de descobrir (TOREN, 2012).

A existência do homem é corporal. E o tratamento social e cultural de que o corpo é objeto fala-nos da pessoa e das variações que sua definição e seus modos de existência conhecem, de uma estrutura social a outra. Segundo Le Breton (2012a), o corpo é um tema particularmente propício a uma análise antropológica porque pertence de pleno direito à estirpe identificadora do homem, estando no cerne da ação individual e coletiva, no cerne do simbolismo social. Cada sociedade, no interior de sua visão de mundo, delineia um saber singular sobre o corpo: seus elementos constitutivos, suas performances, suas correspondências. Ela the confere sentido e valor. As concepções do corpo são tributárias das concepções da pessoa.

Corbin, Courtine e Vigarello (2012) nos apresentam o corpo como "pontofronteira" no cruzamento do invólucro individualizado com a experiência social, da referência subjetiva com a norma coletiva. Exatamente por isso, o corpo está no centro da dinâmica cultural. Do corpo nascem e se propagam as significaçôes que fundamentam a existência individual e coletiva; ele é o eixo da relação com o mundo, o lugar e o tempo nos quais a existência toma forma da fisionomia singular de um ator (CORBIN; COURTINE; VIGARELLO, 2012). 
Seguindo o percurso do texto de Le Breton (2012a), entendemos que, ao nascer, a criança é constituída pela soma infinita de disposições antropológicas das quais só a imersão no campo simbólico, isto é, a relação com os outros, poderá permitir o desenvolvimento. São necessários à criança alguns anos antes que seu corpo esteja inscrito realmente, em diferentes dimensóes, na teia de significações que cerca e estrutura seu grupo de pertencimento. $\mathrm{O}$ autor tece suas considerações a respeito da construção do corpo simbólico. Perguntamonos sobre o intricado processo de construção de sentidos a partir de um corpo biológico ele mesmo em processo de construção gradual, dolorosa, cirúrgica. São os corpos das crianças que nascem com malformações, algumas delas demandando múltiplas reparações. Sem falar na instalação de orifícios não naturais - colostomias, gastrostomias, etc.

Situaremos nossa discussão a partir da experiência de mulheres confrontadas com a tarefa de se fazerem mães de crianças marcadas por uma grave condição crônica de saúde, a síndrome do intestino curto. A maior parte delas gerou um bebê com o intestino exteriorizado - condição com o nome de gastrosquise - e vem recebendo desde a gestação uma série de notícias difíceis e prognósticos sombrios. Outra parte destas mães teve seus filhos atingidos pelas sequelas de infecções e outros eventos originados no período perinatal.

A escolha pela síndrome do intestino curto deve-se a ser esta uma condição clínica crônica, muito grave e de etiologia neonatal em $80 \%$ dos casos em pediatria. (MARTINEZ et al., 2011) A síndrome é caracterizada pela perda anatômica e/ou funcional de parte do intestino delgado e pela consequente deficiência na absorção de nutrientes. Condiçôes como atresias, gastrosquise, volvo e enterocolite necrotizante podem ter como consequência a síndrome do intestino curto e a insuficiência intestinal (MARTINEZ et al., 2011).

Essas crianças são parte do novo segmento discutido por Moreira e Goldani (2010), que se mostra desafiador para o campo da saúde da criança e do adolescente, constituindo um estrato reconhecido como vivendo com condições crônicas complexas de saúde (BURKE; ALVERSON, 2010; COHEN et al., 2011) Os bebês que sobrevivem graças ao acesso às tecnologias modernas e sofisticadas compóem uma nova clientela que precisa ser atendida nos serviços de saúde, e que demanda um alto nível de cuidado e custo para a família e a sociedade mais ampliada. Esse impacto vem sendo objeto de estudos que dão 
relevo à necessidade de reorganização familiar e ao estresse a que os cuidadores estão expostos (CASTRO; PICCININI, 2002; LEITE et al., 2012; SILVA et al., 2010; VIEIRA; LIMA, 2002).

Moreira e Goldani (2010) enfatizam a especificidade da assistência à saúde dedicada a prestar cuidados por longos períodos, muitas vezes durante todo o ciclo vital do indivíduo. É a esta especificidade que precisamos responder com a produção de novos conhecimentos sobre as crianças e adolescentes vivendo com condiçôes crônicas de saúde e sobre o atendimento prestado a elas e seus familiares. Em metassíntese publicada em 2002, são identificados quatro momentos comuns à experiência de ser mãe de filhos com diferentes condiçõos de saúde ou deficiências: a fase inicial de se tornar mãe, a negociação de uma nova forma de maternidade, lidar com a vida que não mais será a mesma e o processo de aceitação/negação. $\mathrm{O}$ estudo destaca, neste quarto passo, o compromisso emocional entre aceitar o filho como ele é sem, contudo, perder a esperança de uma melhora. Esse aparente paradoxo seria fundamental para o bem-estar das mães (NELSON, 2002).

O objetivo do artigo é analisar as interpretaçōes e construções maternas relacionadas ao corpo da criança, articulando-as com a literatura socioantropológica.

\section{Método}

Este artigo se refere a uma pesquisa maior desenvolvida entre julho e outubro de 2014, aprovada por Comitê de Ética em Pesquisa sob o número CAAE 31173614.6.0000.5269, e não contou com financiamento. Seus participantes foram dez mães de crianças com diagnóstico de síndrome do intestino curto, cujos filhos são tratados em um hospital de referência situado no município do Rio de Janeiro, e que foi o local do estudo. O hospital foi mantido em anonimato, e as mães tiveram seus nomes trocados, a fim de preservar a confidencialidade. Foram incluídas as mães de crianças com diagnóstico de síndrome do intestino curto e que estivessem em tratamento, quer internadas ou em acompanhamento ambulatorial. Não trabalhamos com critérios de exclusão, pois interessava-nos apreender a multiplicidade de situações encontráveis nesta população. A pesquisa teve como objetivo geral explorar o processo de construção da maternidade na experiência de ser mãe de uma criança com síndrome do intestino curto. 
Assumimos o método biográfico conforme compreendido por Kornblit (2007), que é o conjunto de técnicas metodológicas baseadas na indagação sobre as histórias de vida. As histórias, tais como são relatadas pelos próprios sujeitos, são relevantes por proporcionarem acesso à multiplicidade de sentidos atribuídos pelas pessoas aos acontecimentos vitais que atravessam, em um contexto social que prima pela diversidade de referências, muitas vezes contraditórias entre si. Essas mães constroem uma biografia a partir do nascimento de um filho com uma condição de saúde que desafia o desenvolvimento esperado.

Cabe diferenciar histórias de vida stricto sensu dos relatos de vida. Enquanto as primeiras implicam em geral um rastreamento detalhado da trajetória vital de uma pessoa, os relatos de vida são narrativas biográficas que, ainda que possam abarcar a amplitude da experiência de vida de uma pessoa começando por seu nascimento, se centram em um aspecto particular desta experiência (KORNBLIT, 2007). No caso desta pesquisa, o aspecto central explorado é o de ser mãe de uma criança com diagnóstico de síndrome do intestino curto.

As experiências particulares recolhidas através das histórias ou relatos de vida representam a possibilidade de recuperar os sentidos vinculados. Ao mesmo tempo que permitem vislumbrar um mundo de significações, apresentam também o desafio de voltar a inserir os sentidos individuais atribuídos à experiência ao contexto social no qual surgem, única via de transcender o particular e construir um saber mais denso sobre o social (KORNBLIT, 2007).

Foi utilizado um roteiro que propiciou a produção de narrativas sobre a trajetória/história das mulheres como mães de crianças cronicamente adoecidas. A questão principal, que abriu a entrevista, foi: "conte-me sua história como mãe de X”. A partir deste relato, as outras questôes foram se colocando na medida em que se tornaram pertinentes. $\mathrm{O}$ destaque foi colocado na exploração dos sentimentos, desafios, expectativas e estratégias encontradas para aprender a cuidar deste filho e se assumir como mãe. As entrevistas foram gravadas e transcritas para análise posterior.

A partir de um contato com a coordenadora de um dos ambulatórios frequentados pelas crianças, pudemos identificar uma profissional que é referência no atendimento às crianças com síndrome do intestino curto e que se tornou uma informante privilegiada para o desenvolvimento da pesquisa. Esta pessoa não 
apenas nos deu acesso ao agendamento dos pacientes com este diagnóstico, como fez contatos telefônicos para nos avisar sobre novas marcações ou alterações na agenda. Nos dias previamente conhecidos, portanto, a pesquisadora permaneceu no referido ambulatório aguardando a chegada das mães. Estas foram abordadas antes da consulta e, após a leitura e assinatura do termo de consentimento livre e esclarecido, entrevistadas na sala de espera. Apesar de não serem estas as condiçōes ideais, compreendemos que qualquer outro arranjo teria provocado desconforto nas entrevistadas que, com toda a justiça, não queriam perder sua vez na sequência dos atendimentos. Buscamos um posicionamento na sala que preservasse o máximo possível o conteúdo dos relatos.

$\mathrm{O}$ fato de a pesquisa ter sido realizada na instituição onde a pesquisadora trabalha e onde as participantes têm seus filhos atendidos gerou a necessidade de uma postura crítica e reflexiva (VELHO, 2003). Partimos, portanto, da premissa de que nenhuma pesquisa é isenta e que o pesquisador não é neutro, fazendo-se necessário o exercício de distanciamento em relação às próprias ideias preconcebidas. Apesar da garantia de anonimato e da garantia da não interferência no tratamento do filho, é possível que algumas mães tenham evitado relatar episódios ou situaçôes que, em seu próprio julgamento, pudessem desqualificá-las. Podemos considerar, entretanto, que a tendência a apresentar-se da melhor maneira está presente no encontro humano, não sendo diferente em outras situações.

Optou-se por uma análise narrativa baseada na adaptação de Moreira et al. (2014), a partir da hermenêutica de profundidade de Thompson. Esta póe relevo no fato de que o estudo das construções simbólicas é, fundamental e inevitavelmente, uma questão de compreensão e interpretação (THOMPSON, 1998). As narrativas apresentam histórias que se compõem quase sempre de uma constelação de personagens e de uma sucessão de eventos, combinados de maneira a exibir certa orientação ou "enredo" (THOMPSON, 1998).

A interpretação dos dados, dialogada entre a hermenêutica de profundidade de Thompson e o interacionismo simbólico, permitiu não ignorar a "ordem macro", mas reconheceu e valorizou o fato de que as construçôes da maternidade incorporam fenômenos de ordem macro e micro que se inscrevem na ordem da interação. 
Foram entrevistadas dez mulheres, sendo que uma delas, avó de uma menina com síndrome do intestino curto, foi incluída por ser atualmente sua cuidadora principal. Ainda assim, mantivemos a entrevista da mãe da criança. Temos, portanto, dez mães e nove crianças (quadro 1).

Chama-nos a atenção a idade das entrevistadas, muito jovens. Com exceção do sujeito 1 (avó), a média de idade atual é de 24,5 anos. A média de idade em que se tornaram mães das crianças em questão é de 21 anos. A cor considerada foi a autorreferida, que por vezes não coincidiu com a avaliação da pesquisadora: cinco mulheres se nomeiam brancas; três, negras; e duas, pardas.

Apenas três mulheres completaram o ensino médio. Das dez mulheres entrevistadas, seis têm um companheiro. Das nove crianças, cinco recebem benefício da assistência social. Apenas duas das entrevistadas trabalham regularmente e uma refere fazer faxinas eventuais para complementar a renda doméstica.

Cinco entrevistadas se declararam evangélicas, das quais duas se disseram afastadas da igreja; três mulheres se declararam católicas, das quais uma afirmou também frequentar a igreja evangélica; duas mães afirmaram não ter religião, sendo que uma desejou acrescentar que acredita em Deus.

Apenas uma das entrevistadas voltou a engravidar após a experiência de ser mãe de uma criança com síndrome do intestino curto. Uma das mães já tinha duas filhas mais velhas e outra tinha um bebê quando o primeiro filho adoeceu.

Quadiro 1. Caracterização das mulheres participantes da pesquisa

\begin{tabular}{|c|c|c|c|c|c|c|c|}
\hline Mulher* & Idade & Cor & Escolaridade & $\begin{array}{l}\text { Presença de } \\
\text { Companheiro }\end{array}$ & $\begin{array}{l}\text { Renda } \\
\text { familiar }\end{array}$ & Religião & $\begin{array}{l}\text { Outros } \\
\text { filhos? }\end{array}$ \\
\hline 1- Ana & 53 & branca & $\begin{array}{c}1^{\circ} \text { grau } \\
\text { completo }\end{array}$ & não & \multirow{2}{*}{$\begin{array}{c}\text { Salário- } \\
\text { mínimo + } \\
\text { LOAS }\end{array}$} & $\begin{array}{c}\text { católica, mas } \\
\text { frequenta } \\
\text { também a } \\
\text { evangélica }\end{array}$ & $\begin{array}{l}2 \text { filhas (é avó } \\
\text { da paciente) }\end{array}$ \\
\hline 2- Carla & 24 & branca & $\begin{array}{c}2^{\circ} \mathrm{grau} \\
\text { incompleto }\end{array}$ & não & & evangélica & $\begin{array}{l}\text { teve um } 1^{\circ} \\
\text { filho que } \\
\text { faleceu aos } \\
4 \mathrm{~m}\end{array}$ \\
\hline
\end{tabular}

continua... 


\begin{tabular}{|c|c|c|c|c|c|c|c|}
\hline Mulher* & Idade & Cor & Escolaridade & $\begin{array}{c}\text { Presença de } \\
\text { Companheiro }\end{array}$ & $\begin{array}{c}\text { Renda } \\
\text { familiar }\end{array}$ & Religião & $\begin{array}{l}\text { Outros } \\
\text { filhos? }\end{array}$ \\
\hline 3- Rita & 25 & branca & $\begin{array}{c}2^{\circ} \text { grau } \\
\text { incompleto }\end{array}$ & $\operatorname{sim}$ & $\begin{array}{c}\text { LOAS } \\
\text { + renda } \\
\text { variável do } \\
\text { marido + } \\
\text { ocasionais } \\
\text { bicos }\end{array}$ & católica & não \\
\hline 4- Teresa & 26 & branca & $\begin{array}{l}2^{\circ} \text { grau } \\
\text { completo }\end{array}$ & não & $\begin{array}{l}\text { não possui } \\
\text { renda fixa } \\
\text { (ajuda de } \\
\text { familiares) }\end{array}$ & $\begin{array}{l}\text { evangélica } \\
\text { afastada }\end{array}$ & $\begin{array}{c}1 \text { filha mais } \\
\text { nova }\end{array}$ \\
\hline $\begin{array}{c}5- \\
\text { Debora }\end{array}$ & 33 & parda & $\begin{array}{c}2^{\circ} \text { grau } \\
\text { incompleto }\end{array}$ & sim & $\begin{array}{l}\text { Salário- } \\
\text { mínimo do } \\
\text { marido + } \\
\text { LOAS }\end{array}$ & $\begin{array}{l}\text { evangélica } \\
\text { afastada }\end{array}$ & $\begin{array}{c}2 \text { filhas mais } \\
\text { velhas }\end{array}$ \\
\hline 6- Flavia & 28 & negra & $\begin{array}{c}2^{\circ} \mathrm{grau} \\
\text { incompleto }\end{array}$ & sim & $\begin{array}{l}\text { Salário- } \\
\text { mínimo } \\
\text { do marido } \\
+ \text { trabalho } \\
\text { informal }\end{array}$ & não tem & não \\
\hline 7- Lucia & 24 & negra & $\begin{array}{c}2^{\circ} \text { grau } \\
\text { incompleto }\end{array}$ & $\operatorname{sim}$ & LOAS & $\begin{array}{c}\text { evangélica, } \\
\text { frequenta } \\
\text { diferentes } \\
\text { denominações }\end{array}$ & $\begin{array}{l}1 \text { filho mais } \\
\text { novo }\end{array}$ \\
\hline 8-Helena & 22 & negra & $\begin{array}{l}2^{\circ} \text { grau } \\
\text { completo }\end{array}$ & $\operatorname{sim}$ & $\begin{array}{c}\text { marido } \\
\text { trabalha } \\
\text { sem carteira }\end{array}$ & $\begin{array}{c}\text { não tem, mas } \\
\text { acredita em } \\
\text { Deus }\end{array}$ & não \\
\hline 9-Diana & 21 & branca & $\begin{array}{c}2^{\circ} \text { grau } \\
\text { incompleto }\end{array}$ & sim & $\begin{array}{c}\text { marido e ela } \\
\text { trabalham }\end{array}$ & católica & não \\
\hline 10-Aline & 18 & negra & $\begin{array}{l}2^{\circ} \text { grau } \\
\text { completo }\end{array}$ & não & $\begin{array}{c}\text { ajuda da } \\
\text { família + } \\
\text { LOAS }\end{array}$ & evangélica & não \\
\hline
\end{tabular}

* Nomes fictícios.

Fonte: elaboração própria 
Com relação às crianças, seis eram meninas e três meninos. Dentre as nove, quatro delas têm agora cinco anos de idade, duas têm três anos, duas têm um ano e uma das crianças tinha nove meses no momento da entrevista com sua mãe. Não é coincidência o fato de não termos entrevistado mães de crianças mais velhas. Os filhos de Rita, Debora e Lucia (entrevistas 3, 5 e 7) são as primeiras crianças com SIC em tratamento a sobreviverem no hospital especializado onde a pesquisa foi conduzida. A situação do filho de Teresa (entrevista 4) é diferente. Ele tem cinco anos, e teve o intestino seccionado aos três anos de idade em consequência de um volvo intestinal (torção de uma alça do intestino). Todas as outras crianças convivem com a síndrome desde o período neonatal.

Fora o menino que apresentou um quadro de volvo intestinal (entrevista 4) e a filha de Carla (entrevista 2), que sofreu uma enterocolite necrotizante (infecção grave) nos primeiros dias de vida, todas as outras crianças nasceram com gastrosquise (malformação abdominal com exposição de partes do intestino ao nascer).

Quanto às estomias, uma criança tem gastrostomia, duas têm ileostomia e uma tem tanto a gastrostomia como a ileostomia; cinco crianças não têm estomias atualmente, sendo que destas uma já teve gastrostomia e uma já teve ileostomia.

A média de duração da primeira internação foi de 11 meses, mas devemos considerar que duas internaçóes ainda estavam em curso no momento das entrevistas. Os dados não foram checados em prontuário, pois interessa-nos, mais do que a exatidão, a informação conforme transmitida pela mãe.

\section{Discussão}

No processo de análise e interpretação dos dados, ganharam destaque dois campos de tensão que estruturam o processo de construção de maternidade: 1) um filho que desafia a condição humana e tudo aquilo que seria esperado; e 2) um filho que expressa com seu corpo significados que motivam interpretaçôes, um sujeito que se constrói na intimidade com sua mãe, ao largo das mediações promovidas na internação hospitalar.

A primeira interpretação aponta para um campo de significação onde está presente um questionamento das mulheres sobre uma suposta "natureza humana” e o quanto seus filhos a desafiariam. De alguma forma, esta criança 
que não mama, cujo corpo terminou de ser construído pelas mãos do cirurgião e que cresceu no hospital sob a guarda de profissionais de saúde subverte a "ordem natural" na interpretação materna. Podemos depreender das falas das mães das crianças com SIC alguns desses signos da normalidade.

[...] quando a gente engravida a gente imagina um bebê, uma vida. Aí você pensa que vai engravidar, vai nascer, vai sair do hospital e vai cuidar em casa. Aí você engravida, nasce com problema, fica aquele tempo internado e sem expectativa de vida. (Rita, 25 anos).

Normal é, portanto, a mãe cuidar de seu bebê saudável em casa, imaginando que este terá uma vida pela frente.

Helena, que no dia em que foi entrevistada acompanhava a filha que nunca havia ido para casa, assim se refere a sua situação:

No meu bairro, nenhuma criança que nasceu ficou quase nove meses no hospital. É estranho [...] (Helena, 22 anos).

Essa criança que não pode ir para casa como todas as outras carrega também em seu corpo as marcas da estranheza. São orifícios não naturais, ou estomias, destinados à alimentação e/ou excreção. O cateter na veia possibilita a administração da nutrição parenteral. As funções fisiológicas são subvertidas, artefatos tecnológicos fazem suplência às deficiências orgânicas.

Ele nunca mamou, ele tinha gastrostomia, "ele nunca vai poder se alimentar pela boca” (foi dito à mãe). Ele é uma criança que tudo dele vai ser devagar. (Rita, 25 anos).

É um corpo estranho, porque ninguém tem um cateter no corpo. (Aline, 18 anos).

No nível mais objetivo, Aline está dizendo que o "corpo estranho" é o cateter. Entretanto, se considerarmos que "ninguém tem um cateter no corpo", o "corpo estranho" pode ser o corpo da sua filha. Normal é ser amamentado, comer pela boca, não ter gastrostomia e nem cateter.

A amamentação é na sociedade brasileira contemporânea uma experiência tão definidora da maternidade e da relação mãe-bebê que uma criança que não possa ser amamentada pode significar para a mãe um desafio à natureza. Debora tentou oferecer o seio à filha quando esta pôde finalmente comer pela boca. A criança o rejeitou.

Ela rejeita a própria natureza dela. Acho que quando ela tiver um filho ela nem vai querer amamentar. (Debora, 33 anos). 
Podemos compreender que uma criança que não mama nos primeiros meses

de vida não aceitará o seio aos dois anos de idade. Aqui nos importa, entretanto, como a situação foi significada por Debora.

As próprias pessoas da minha família viam ele e era como se estivessem vendo uma coisa de outro mundo. Como se você tivesse visto pela primeira vez uma coisa que você nunca viu, você não fica surpresa? (Rita, 25 anos).

A natureza rejeitada, uma coisa do outro mundo. Estaria negada a essas crianças uma humanidade? Rodrigues (2010) nos diz que há na corporeidade e na natureza do homem de modo geral uma contradição fundamental: a de ser ele ao mesmo tempo um ser da natureza (isto é, um animal) e algo diferente de um animal (um ser cultural). "Ao erigir-se em símbolo da estrutura social, o corpo, simultaneamente natureza e representante da cultura, condensa em si esta ambiguidade e reproduz simbolicamente ao mesmo tempo o que a sociedade deseja e o que a sociedade teme" (RODRIGUES, 2010, p. 149).

O corpo modificado por cirurgias, portador de novos orifícios, pode parecer às mães "inumano" no sentido de não natural. Entretanto, paradoxalmente, assim como exibe artefatos tecnológicos, o corpo destas crianças oferece um contato com a natureza em seu estado mais bruto. As entranhas, as secreçōes, tudo que costumeiramente se encontra oculto, é exposto e comparece no campo da interação.

O corpo da criança aparece nas narrativas como personagem principal. Este corpo - em lugar de cabeça, tronco e membros - parece ser composto por intestino (ou simplesmente "alça", de alça intestinal), "cirurgia" (termo pelo qual as mães se referem à ferida operatória ou cicatriz), "veia”, cateter e estomias. Os atributos do corpo são a imprevisibilidade e a violência de suas manifestações.

A violência se traduz nos relatos das mães pela escolha de palavras vívidas, gráficas. Os termos técnicos diversas vezes empregados não camuflam o espanto. São relatos que geram desconforto na pesquisadora.

[...] o intestino furou e começou a vazar resíduo gástrico para dentro do corpo dele. (Rita, 25 anos).

Teve que correr para o Centro Cirúrgico e começar a cortar e a emendar (o intestino). (Rita, 25 anos).

Às vezes uma alça dobrava, às vezes uma alça estava entupida, às vezes uma alça estava dilatada. (Debora, 33 anos). 
Ela (a criança) estava tão inchada, sabe, parecia que ia explodir, inchadona, amarelada. (Debora, 33 anos).

Ela foi inchando e aí foi esticando e estourou os pontos. (Aline, 18 anos).

A apropriação por parte das mães de alguns termos do vocabulário médico parece apontar para uma tentativa de apreensão de uma realidade que é por demais ameaçadora e incompreensível. Para além deste dado, aqui se ressalta a brutalidade das vivências nos corpos das crianças e, consequentemente, na experiência de suas mães.

As estomias, principalmente quando recém-instaladas, podem gerar horror. Falando da gastrostomia de sua filha, Aline nos diz:

Eu já tinha visto button (tipo de sonda normalmente utilizado após um tempo da instalação da gastrostomia), ou a sonda branquinha. Aí no dia, era um negócio grande, coral, saía um monte de troço verde. Porque o problema dela também é resíduo. Quando ela opera fica mais de um mês saindo resíduo. (Aline, 18 anos).

Há, portanto, duas fontes de desconforto: a presença de algo artificial (o "negócio grande, coral" - uma sonda) e o comparecimento de algo por demais natural ("um monte de troço verde" - resíduo gástrico).

Em sua análise do nojo, Rodrigues (2010) associa as secreções do corpo a um "interior" tenebroso, sendo sua manifestação "exterior" um deslocamento e sempre uma agressão. $\mathrm{O}$ nojo dos produtos do corpo expressaria, antes de qualquer coisa, a reação a uma transgressão ou um perigo sobre os limites entre a natureza e a cultura. O horror às manifestações corporais é uma espécie de fascínio que estas exercem sobre o homem, porque a ele evocam, obscuramente, algo que é seu, algo que é ele, mas em que não pode reconhecer-se. Abriga em nós um inferno: a natureza humana que é estranha aos homens (RODRIGUES, 2010).

Este é o paradoxo que o corpo destas crianças nos apresenta: são cultura e natureza em intensidade máxima.

Uma larga rede de expectativas corporais recíprocas condiciona as trocas entre os parceiros sociais, iniciando pela primeira relação que é a da mãe com seu bebê. As experiências somáticas espelham-se umas nas outras (LE BRETON, 2012b). O nascimento de uma criança com malformações graves torna não aplicáveis ou insuficientes as conhecidas normas familiares sobre atenção, reconhecimento e cuidados com bebês. Crianças cuja forma de estar no mundo e a própria sobrevivência estão condicionadas à subversão das formas de alimentação, 
respiração e/ou excreção. Os pais, na maioria das vezes, creem saber pouco sobre este filho cujo reconhecimento percorre essencialmente aspectos clínicos (MORSCH et al., 2012).

É possível identificar nas entrevistas o sentimento de exclusão e alheamento produzido nas mães pelo aparato de cuidados técnicos que cerca seus filhos desde o nascimento. Sobre os primeiros momentos de sua filha, que nasceu com gastrosquise - e, portanto, com o intestino exteriorizado necessitando de proteção com o objetivo de ser preservado - uma mãe se refere ao bebê "todo embrulhado em plástico”. A mesma mãe diz só ter pego sua filha no colo aos cinco ou seis meses. Outra mãe, cujo filho nasceu em condições semelhantes, relata: "Eu só sentava e ficava olhando ele deitado".

A anatomia não é um destino, porquanto sociedades e atores a simbolizam à sua maneira. Mas ela se torna, com efeito, uma condenação quando o homem se vê privado de figurar outra coisa que não seus atributos corporais (LE BRETON, 2012b). Quando o corpo se torna mistério, não sabemos mais como abordá-lo. As expectativas dos atores não mais se respondem. É gerado um afastamento que apresenta o risco de reduzir a criança a um corpo somático de necessidades arbitrariamente definidas, desenraizado de toda existencialidade, sem história, sem qualidades, simples volume. Ele pode ser concebido para "funcionar" em lugar de viver (LE BRETON, 2012b).

O segundo campo de interpretações forma um conjunto bem diferente. $\mathrm{Na}$ interpretação das mães, é possível ver uma trajetória que culmina com o reconhecimento do filho como alguém que tem uma condição de existência diferente, mas afirmativa de vontade e expressão:

O meu filho tem muita vontade de viver, eu acho que ele tem muito mais vontade de viver do que a gente que está perto de querer ver ele vivo, entendeu? Ele tem muita força de vontade de viver (Rita, 25 anos).

Aí ela olhava com aquele olhinho para mim e eu disse: "É, você veio para vencer, você veio para ficar" (Debora, 33 anos).

A interpretação das mães de gestos, olhares e reações estão baseadas no reconhecimento de uma intencionalidade por parte dos filhos. A intencionalidade e a dimensão intersubjetiva do encontro, tão caras aos interacionistas simbólicos, são a garantia da condição humana em ação. E isso parece estar presente no exercício de interpretação e de construção de significado de ser mãe de uma 

ainda na unidade neonatal, relatam:

Ela deu uma virada na incubadora que a alça (intestinal) soltou toda para fora. Tiveram que correr com ela para a cirurgia e aí tiraram a colostomia. Eu falei: "É isso mesmo, minha filha! Não aceita isso na sua vida!” (Debora, 33 anos).

Ela ia precisar colocar a traqueo (traqueostomia), só que de uma hora para a outra, do nada, ela mesma soltou os aparelhos e começou a respirar normal (Carla, 24 anos).

A criança é assim inserida numa ordem de intencionalidade, não mais um corpo passivo que sofre intervenções. Mesmo após a alta hospitalar, ter um filho com intestino curto continua significando, por um longo tempo, lidar com restrições alimentares. Ao falar das dificuldades de seus filhos, as mães referemse espontaneamente às adaptaçôes que vão fazendo e ao seu modo de abordar as situações. Podemos ver nisto a continuidade de uma construção muito particular.

Rita explica ao filho de cinco anos que determinados alimentos "fazem dodói" na barriga.

[...] ele chega no mercado comigo e fala: "mãe, eu queria tanto um Danone...” A dificuldade é de ele ter intolerância à lactose, ele pedir as coisas e você não poder dar. Ele nunca botou na boca, mas ele sabe o que é, que ele vê a prima bebendo e pede. Eu converso: filho, você não pode, porque se não faz dodói na sua barriga... "faz dodói na minha barriga?". Faz. "Ah, então não quero não." Aí eu falo: pega uma fruta, uma maçã, uma banana, a fruta que você quiser. Aí ele vai e pega a fruta (Rita, 25 anos).

Através da conversa e da substituição do alimento (iogurte por fruta) o impasse pôde ser resolvido satisfatoriamente. Esta maneira de lidar contribui para que a criança se aproprie da sua condição.

Ele vai a aniversário com criança, normal. Não evito, porque eu acho que ele tem que crescer sabendo que ele é limitado para certas coisas. [...] Tem umas coisas que hoje ele vê e ele já sabe que ele não pode comer, igual chocolate que ele já vê e fala: "mãe, isso aqui eu não posso que faz dodói na minha barriga, não é?” Aí eu falo: é! (Rita, 25 anos).

Outra entrevistada, Ana, procura recorrer à evitação das situações para a sua neta não "passar vontade".

[...] às vezes ela vê as coisas, aí quer, aí a gente evita mercado. Quando eu vou fazer compras eu não levo ela para o mercado, que ela vê biscoito, vê aquelas coisas, sabe? (Ana, 53 anos).

Quando a gente está na rua, ou vai para o hospital, às vezes as pessoas oferecem biscoito, as coisas, aí a gente faz sinal, fala que ela não pode, a gente sai de perto [...]. Em festa também, às vezes ela é convidada para aniversário, aí a gente não leva. Uma vez 
a minha filha levou, [...] eu peguei torrada, aí picotei, aí botei num potinho e a minha

filha levou, né, para ela. Aí chegou lá, ela ficou vendo o pessoal, as crianças comendo, aí a minha filha teve que sair (Ana, 53 anos).

A evitação chega ao ponto de um sacrifício dos adultos, que deixam de se alimentar por longos períodos e até que seja possível fazê-lo sem despertar a atenção da menina.

É muito difícil, (às vezes a gente) não come. A gente dá um jeito, deixa ela no quarto vendo televisão [...]. Eu só estava almoçando acho que horário de 5 horas... é a hora que a mãe dela chega. Ou então deixava ela no quarto vendo televisão, conversando com ela da cozinha, rapidinho, "vovó já está indo", comia um biscoitinho com água, entendeu? (Ana, 53 anos).

Outra estratégia importante é a aquisição de conhecimentos, muitos deles bastante empíricos, que ajudam as mulheres a cuidarem de intercorrências clínicas em casa. É a "manha”, como nos relata Lúcia.

A (minha filha) faz educação física, faz tudo, passeia muito, só não pode comer de tudo. Antes não podia comer nada, agora come, só não pode comer queijo, beber refrigerante demais, porque aí ela passa mal. Eu já sei porque ela fica com o olho fundo. Ela ficava com o olho fundo, eu trazia para o hospital e a médica internava ela. Hoje não, eu peguei a manha aqui do hospital. Ela está com o olho fundo, eu boto ela para dormir bastante, eu dou soro a ela em casa, não deixo brincar, porque se ela está brincando não melhora o corpo, aí nunca mais internou. Não interna tem mais de ano (Lúcia, 25 anos).

A própria criança vai adquirindo um saber sobre si que se torna fundamental para o manejo materno de eventuais mal-estares corporais.

Ela é criança, mas já conhece o corpo dela. Ela sente alguma coisa, ela mesma pede Luftal (medicação anti-gases), pede soro... É que o organismo dela pede (Lúcia, 25 anos).

Quando a criança é considerada como tendo uma "vida normal", tendo sido, portanto, vitoriosa em sua batalha, as marcas corporais são ressignificadas. Não mais (apenas) um estigma, a cicatriz cirúrgica - ou simplesmente "cirurgia" na fala das mães - passa a ser um símbolo desta luta. Debora e Teresa, justamente as mães de duas das crianças mais "normais" do grupo, tiveram a atitude de levantar as blusas de seus filhos e mostrar-me tais marcas cirúrgicas. Debora mostrou ainda, no corpo da filha, as cicatrizes deixadas pelos muitos acessos venosos feitos durante a internação. Todo o processo foi feito de forma muito lúdica: "Ela foi furada aqui, aqui, aqui...”, dizia a mãe, fazendo cócegas em cada um dos pontos. A criança ria com gosto. 
A grande cicatriz arredondada no abdome pôde ser ressignificada como um símbolo de vitória, de superação, marca de uma diferença positiva. "É o meu solzinho" - me diz a menina. "Eu acho que se ela tivesse nascido normal ia ser estranho." - diz Debora - "Estranho assim, não ia ser o que é hoje. [...] Porque o que ela é hoje é devido ao que ela passou. Se tivesse que passar por tudo, eu passava de novo".

\section{Considerações finais}

Cabe assumir o desafio de investir em pesquisas com crianças que carregam as marcas das condições crônicas complexas de saúde. Elas representam um estrato da população que epidemiologicamente não é destacado, marcado pela invisibilidade, mas que quando reunidas, por sua condição de raridade, nos revelam aprendizados sobre o enfrentamento das vulnerabilidades a que estão expostas. $\mathrm{O}$ enfrentamento do inesperado e da adversidade no cuidar de uma criança cujas sequelas de uma doença tornam-se marcas de uma condição crônica de saúde pode ser revelador de aprendizagens no manejo, abordagem e construção de vínculos. Esperamos desta forma contribuir para uma visão mais integral do processo de adoecimento, que tem múltiplo impactos para além dos biológicos.

O nascimento de crianças com malformações graves, necessariamente mediado por aparatos tecnológicos e por cuidados especiais, parece gerar um distanciamento e um sentimento de exclusão por parte das mães, que podem se sentir privadas de experiências fundamentais e definidoras da maternidade. No espaço contemporâneo da divulgação de campanhas ligadas à maternidade e à saúde do bebê que se estendem à primeira infância, o ato de oferecer o seio e o leite como alimento se revela como um marco na biografia de mulheres que experienciam a maternidade, assim como o contato inicial pele a pele e a garantia de alojamento conjunto. Para além dos benefícios inegáveis e reconhecidos destas práticas, precisamos observar que esse campo científico e sanitário pode gerar imperativos morais que excluem simbolicamente mulheres que têm uma vivência inicial diferente da maternidade.

Os filhos da tecnologia precisam ser adotados por suas próprias mães para que se possam constituir subjetivamente como humanos. Faz-se necessário reconhecer que o processo de maternar um bebê se dá num ambiente relacional, de construção de referências recíprocas, de alteridade. $\mathrm{O}$ fato de 
essas mulheres terem adiado o momento de ter seus filhos consigo, deixandoos em internaçóes prolongadas, sob cuidados profissionais, acaba por ser um fator complicador para a construção do vínculo. Considera-se ainda que o processo de tratamento, agravamentos, recuperação e prognóstico, em muito cercado de incertezas, gera nessas mulheres um estado constante de alerta. O processo de construção de uma filiação nesses casos, por ter como cenário a instituição hospitalar e ser atravessada por seus aparatos, passa necessariamente pela mediação dos profissionais de saúde de referência.

Ainda que fundamental para o bebê, o amor materno não pode ser prescrito, não pode ser treinado, não pode ser cobrado. $\mathrm{O}$ amor é construído a partir de encontros em que a criança é reconhecida como parceira ativa e nos quais a mulher se sente importante, fundamental. Para além do treinamento para administrar uma dieta ou cuidar de uma estomia, para além da cobrança de uma presença física nas unidades de internação, penso que as mães precisam ser convidadas carinhosamente a ocupar seu espaço junto aos filhos trazendo sua singularidade. Isso inclui sua história, seus laços, seus medos e sonhos, tudo enfim que as tornam humanas. Para que possam ser elas mesmas mães de seus filhos, precisam ser ajudadas a enxergar e se apropriar das crianças, que assim se constituirão para além de qualquer diagnóstico ou prognóstico.

É necessário rever uma certa perspectiva utilitarista e racional que está embutida nos projetos de treinamento que pensam a permanência, transferência e alta dessas crianças, e dizem respeito à performance esperada do que seja uma mãe com seu filho em um hospital. Isso inclui estarmos atentos às construções subjetivas e aos modelos culturais que provocam sofrimentos e dificuldades na construção de vínculos.

Mesmo na radicalidade de condiçôes tão dramáticas como as que pudemos contemplar, devemos considerar que o homem não é produto do corpo, ou seja, a corporeidade ésocialmente construída, e está estreitamenteligada intencionalidade. O organismo malformado não representa uma condenação, ele não determina por si um destino disforme. A interpretação das mães injetando intencionalidade nos gestos corporais de suas crianças é um fundamento de garantia de sua humanidade, ainda que na diferença radical de um corpo fora dos padrões. Emissor ou receptor, o corpo produz sentidos continuamente e assim insere o homem, de forma ativa, no interior de dado espaço social e cultural (LE BRETON, 2012a). 
Para Le Breton (2012a), tateando suas marcas, o ator empenha-se por produzir um sentimento de identidade mais favorável. Finalizamos registrando a esperança de que, através do compartilhamento de muitos sentidos e da abertura de múltiplas possibilidades, possamos acompanhar a construção de íntegros corpos desejantes. ${ }^{1}$

\section{Referências}

BURKE, R.T.; ALVERSON, B. Impact of children with medically complex conditions. Pediatrics, v. 126, n. 9, p. 789-790, 2010.

CASTRO, E.K.; PICCININI, C.A. Implicações da doença orgânica crônica na infância para as relações familiares: algumas questôes teóricas. Psicologia: reflexão e crítica, v. 15, n. 3, p. 625-635, 2002.

COHEN, E. et al. Children with medical complexity: an emerging population for clinical and research initiatives. Pediatrics, v. 127, n. 3, p. 529-538, 2011.

CORBIN, A.; COURTINE, J.J.; VIGARELlO, G. Prefácio à História do Corpo. In: CORBIN, A.; COURTINE, J.J.; VIGARELlO, G. História do Corpo: da Renascença às Luzes. 5a. ed. Petrópolis: Vozes, 2012. p. 7-13.

KORNBLIT, A.L. Metodologías cualitativas en ciencias sociales - Modelos y procedimientos de análisis. Buenos Aires: Biblos, 2007. p. 15-31.

LE BRETON, D. A sociologia do corpo 6a. ed. Petrópolis: Vozes, 2012. p. 7-38.

. Antropologia do corpo e modernidade 2a. ed. Petrópolis: Vozes, p. 7-15 e 141-221, 2012.

LEITE, M.F. et al. Condição crônica na infância durante a hospitalização: sofrimento do cuidador familiar. Cienc Cuid Saude, v. 11, n. 1, p. 51-57, 2012.

MARTINEZ, M. et al. Evolución y sobrevida de pacientes pediátricos con síndrome de intestino corto (SIC). Nutrición Hospitalaria v. 26, n. 1, p. 239-242, 2011.

MOREIRA, M.C.N. et al. Violência contra crianças e adolescentes com deficiência: narrativas com conselheiros tutelares. Ciênc. saúde coletiva, v. 19, n. 9, p. 3869-3878, 2014.

MOREIRA, M.E.L.; GOLDANI, M.Z. A criança é o pai do homem: novos desafios para a área de saúde da criança. Ciênc. saúde coletiva v. 15, n. 2, p. 321-327, 2010.

MORSCH et al. Redes de suporte à parentalidade em UTI neonatal: um relato de experiência. In: PICCININI, C.A.; ALVARENGA, P. Maternidade e paternidade - a parentalidade em diferentes contextos. São Paulo: Casa do Psicólogo, 2012. p. 59-82.

NELSON, A.M. A metasynthesis: mothering other-than-normal children. Qual Health Res. v. 12 , n. 4 , p. 515-530, 2002. 
RODRIGUES, J.C. Tabu do corpo $7^{\mathrm{a}}$. ed. rev. Rio de Janeiro: Editora Fiocruz, 2010. p. 115-150.

SCHRAMM, F.C. Bioética e biossegurança. In: COSTA, S.I.F.; OSELKA, G.; GARRAFA, V. Iniciação à bioética. Brasília: Conselho Federal de Medicina, 1998. p. 217-230.

SILVA, M.A.S. et al. Cotidiano da família no enfrentamento da condição crônica na infância. Acta Paul Enferm, v. 23, n. 3, p. 359-365, 2010.

THOMPSON, J.B. Ideología y cultura moderna. 2a. ed. Coyoacán: Universidad Autónoma Metropolitana, p. 395-473, 1998.

TOREN, C. Antropologia e psicologia. Revista Brasileira de Ciências Sociais, v. 80, n. 27, p. 21-36, 2012.

VELHO, G. O desafio da proximidade. In: VELHO, G.; KUSCHINIR, K. (org.) Pesquisas urbanas. Desafios do trabalho antropológico. Rio de Janeiro: Zahar, p. 123-132, 2003.

VIEIRA, M.A.; LIMA, R.A.G. Crianças e adolescentes com doença crônica: convivendo com mudanças. Rev Latino am Enfermagem, v. 10, n. 4, p. 55-60, 2002.

\section{Nota}

${ }^{1}$ A. Paez realizou a pesquisa, a análise dos resultados e redigiu o artigo. M. C. N. Moreira supervisionou a realização da pesquisa, a análise dos dados e revisou a versão final do artigo. 


\section{Abstract}

\section{Building motherhood: experiences of mothers of children with short bowel syndrome}

The experience of mothers of children diagnosed with a severe chronic health condition, short bowel syndrome (SBS), has been addressed by a study that took place in a referral hospital in Rio de Janeiro in 2014, with 10 participants. This paper aims to explore aspects of maternal interpretation of the corporeality of babies and its effect on the construction of motherhood. The biographical method has been used, and an interview guide that led to the production of narratives. The interpretation of data, through a dialogue between the hermeneutic depth of Thompson and symbolic interaction, recognized and appreciated the fact that maternity constructions are inscribed in the order of interaction. The different bodies, which seem to defy the human condition in the interpretation of mothers, acquire meaning and intentionality. The dimension of intersubjectivity guarantees the recognition of the baby. The paper concludes that technological devices and special care triggered for the survival of babies with severe malformations may generate a detachment and a sense of exclusion by mothers. Addressing these women must transcend the utilitarian practices based on a "training" of care.

> Key words: maternity; short bowel syndrome; body; chronic disease; children. 